\title{
Lean and Agile model implementation for managing the supply chain
}

\author{
Youssef HASSANI \\ Bucharest University of Economic Studies, Bucharest, Romania \\ hassani.youssri@gmail.com \\ Ioana CEAUȘU \\ Bucharest University of Economic Studies, Bucharest, Romania \\ ioana.ceausu@fabiz.ase.ro \\ Adrian IORDACHE \\ Bucharest University of Economic Studies, Bucharest, Romania \\ adi.iordache@gmail.com
}

\begin{abstract}
Even though both researchers and practitioners propose several approaches to supply chain management research and the scientific literature shows that several methods have been implemented for supply chain management, the studies carried out have not revealed a formalized process or a clear method for supply chain integration. Indeed, there is a specific way to achieve this integration in the supply chain and there are differences in how one company does it compared to another. More recently, an alternative based on the Lean and Agile paradigms has been presented. The implementation of the Lean and Agile models to the supply chain aims to improve and simplify the production and the process of minimizing or eliminating wastes of all kinds, raise the productivity of the supply chain, increase the capability to respond quickly to unpredictable and changing customer demands and to take advantage of the uncertainty and the volatility of the market in the medium term. The main objective of this paper is to conduct an impact study on the implementation of Lean and Agile models in the supply chain, based on a review of the scientific literature concerning the models implemented to improve the productivity of the supply chain. We aim to identify and analyze the research carried out regarding the implementation of Lean and Agile models in order to improve the supply chain management, the results achieved and future research directions. Although the Lean and Agility paradigms are distinct and can be developed differently, they can be successfully integrated into a well-designed supply chain integration that involves a substantial degree of ambiguity in terms of significance and level of application across different supply chains, in order to increase the capacity to act, react and adapt to changes in demand and supply.
\end{abstract}

Keywords: supply chain management, lean Model, agility, Lean and Agile Supply Chain, digital world.

\section{Introduction}

To gain a competitive advantage, companies apply modern supply chain management methods and techniques with the aim of increasing the competitiveness of all participants of the supply chain by adapting to customer needs and satisfaction.

Due to the diversification of products and services, the costs of changes decrease in the chain of activities, thanks to which the frequent choices made between economic entities become faster and easier. The consequences of the difficulty for a client include continued pressure to expand the range of assortments, offering better additional services, more flexible adjustment of conditions, as well as competitive prices.

It must however be remembered that between the actors of the supply chain, there are links consisting in the integration and optimizing the physical flow which concerns the transfer of 
goods and service to customers, the flow of information which considers itself as a shared resource throughout the supply chain from suppliers to final customers in addition to a financial flow which materializes by the transfer of funds.

However, good management of the supply chain covers forecasts of customer requests, planning and then the manufacture and delivery of the right product or service, at the right place and at the agreed time. Consequently, customer satisfaction is aimed in terms of quality and deadlines at a competitive price, while remaining attentive to market fluctuations and present the essential assets for a "customer satisfaction" oriented strategy (Marquardt et al., 2017).

In this perspective, the literature affirms the connection between the implementation of the Lean and Agile method and the improvement of operational performance. In fact, the practices and principles of these methods aim to reduce waste of all kinds and to provide flexibility in the processes, thereby bringing real benefit to customers (Tortorella et al., 2017). As well, the most successful companies are those that develop and link their improvement processes internally with external customers and suppliers (Frohlich et al., 2001).

Finally, the Lean and Agile concept, supply chain integration must been thought beyond an understanding, which is limited to a simple application at the workstation level. The integration of suppliers and customers is essential.

\section{Literature review}

Improving the performance of the supply chain has attracted the interest of many researchers. Literature is interested in this subject through different concepts and principles; after an initial analysis of the literature, we list below the different approaches and concepts aimed at improving performance:

- $\quad$ Elimination of waste;

- cost reduction;

- $\quad$ improved cooperation, collaboration, coordination in the supply chain;

- Just-In-Time concept; Improvement of the value provided to customers;

- $\quad$ Flexibility and efficiency;

- $\quad$ Resilience and ability to withstand unforeseen circumstances;

- $\quad$ Lean and Agile.

A wide range of publications on supply chain management highlights Lean and Agile concepts that complement each other in achieving competitive advantage. The key features that result from the union of these two concepts has resulted in the concept of "Leagility" (Naylor et al., 1999).

Introducing "Lean Thinking" into the supply chain management has essentially been about improving it, by eliminating waste of all kinds. This is described as "operating efficiency".

On the other hand, the Agility serves the customer by enabling the company to act more efficiently and to overcome the shortcomings of the much older Lean concept.

Reducing costs and creating customer perceived value are therefore important areas (Andelkovic \& Radosavljevic, 2018). This means that all activities along the supply chain need to function and be coordinated appropriately to ensure a global impact on any supply chain.

This is based on the premise that each of these activities cannot guarantee effectiveness alone without interaction with other activities.

Other studies have been documented to show the role of the Lean concept and Agility in a profitable supply chain, as well as how to achieve a Lean and Agile business. Emory et al., note 
that agility-oriented companies are market sensitive and will take advantage of their supply chain operations to respond quickly and profitably to unpredictable changes (Emory et al., 2007).

Their argument rests on the fact that key components of an agile business such as quality, speed, flexibility and responsiveness are necessary to meet the unique needs of customers and markets.

In their book "Agile competitors and virtual organizations: strategies to enrich the customer" Goldman et al., provide answers to the reasons why companies need agility and why this Agility is an integral part of the new industrial order (Goldman et al., 1994). Illustrating how businesses use agility as a strategic framework to manage change and uncertainty, the book clearly documents examples of agility emerging in industries as a strategic way to enrich the customer.

\section{Methodology}

The problem of the current supply chain is a problem that manifests itself at the global level, due to the changes that manifest the customer culture, thus the design of the supply chain.

The literature review did not reveal a formal process or clear methodology for integrating these concepts into the supply chain within an organization. Indeed, there is no specific way to achieve integration in the supply chain and there are even differences in how one company can reach it compared to another. This raises the question of whether a methodology or a model can be taken into consideration and therefore the application can contribute to the management of a successful lean and agile supply chain.

Our contribution brings to travaers this research of theoretical type which aims at the development of a model (according to current dictionaries, a model is a simplified representation of a process or a system) lean and agile for the management of the supply chain based on: data analysis, processing and interpretation of relevant data as well as a study of the literature in accordance with the subject taking into account the context of the market.

\section{Concept of supply chain management}

Faced with a strong globalization, companies are adapting their supply chain to adequately meet the needs of customers; these needs are characterized by immediate availability. As a result, the market is dominated by uncertainty and unpredictability, as the result production, logistics, and supply chain processes are becoming more complex.

According to Kamaruddin et al., the supply chain becomes difficult to manage due to the complexity inherent in dependencies exists between the parties in time and space (Kamaruddin et al., 2009). Complexity and uncertainty are the two main constraints that today's businesses must overcome to be competitive and efficient.

The integration of key business processes across the supply chain for the purpose of creating value for customers and stakeholders (Lambert, 2008). According to Christopher, an organization's supply strategy, operational strategy and orientation to the market must be adapted according to the specificity of the product / market. Fundamental changes in the environment, competition, market trends must been constantly taken into account in the Supply Chain strategy in order to exploit profitable opportunities in a volatile market (Christopher et al., 2006). (Christopher et al., 2000) adds that actors in the supply chain seek to minimize supply lead times to respond swiftly to demand changes.

The approach to supply chain integration was requested by Zhao et al., who considered it a measure to which the company integrates with its supply chain partners to achieve efficient and 
effective information and product flows, by sharing decisions and information of high value and speed and at the lowest costs (Zhao et al., 2008).

The goal of supply chain integration allows customers maximum speed, speed and at low cost while maintaining a flow of information and materials through the integration of customers and suppliers (Flynn et al., 2010).

Generally, supply chain management also involves managing relationships and managing the inflow and outflow of goods, services and information between manufacturers as well as between manufacturers and consumers. The supply chain management processes identified by (Lambert, 2008) are the processes, which concern: customer relationship management; customer service management, demand management, order fulfillment, management of the manufacturing flow, supplier relationship management, product development (Ionescu et al., 2019).

Christopher bases the sustainability and prosperity of companies on the existence of an "agile supply chain" which stimulates adaptability and reactivity in the face of uncertainty and instability linked to products, markets, prices, news technologies and material availability, emphasizing the high level of customer service (Christopher, 2000).

\section{Concept of lean supply chain}

Lean supply chain management is defined as a set of organizations linked together by upstream and downstream flows of information, products, services and funds, they work together to reduce costs and waste by efficiently exploiting what is necessary to meet customer needs. (Vitasek et al., 2005). The literature has shown that there is a positive association between the implementation of the lean management approach and the performance of the principle that it aims to reduce waste and process variability, to add more value to customers and to improve operational performance (Tortorella et al., 2017).

In fact, by reducing the wasted resources of the guaranteed manufacturing system: an increase in productivity, the reduction in costs which will lead to lower prices for the customer and will thus lead to an increase in market share and improve profitability in the long term (Chandan et al., 2013). The adoption of Lean supply chain management implies a model for improving the benefits resulting from cooperation rather than the imposition of power on supply chain partners (Tortorella et al. 2017).

The goal of Lean manufacturing is to reduce waste in human effort, inventory, time to market and manufacturing space to become very responsive to customer demand while producing quality products in the most efficient and economical way (Chen et al, 2013). According to Fachman, the lean management of a supply chain is based on four main objectives, which are elimination of waste, obtaining regular flows, efficient customer service and improvement quality (Fachmann, 2013).

\section{Concept of supply chain agility}

Supply chain agility is generally defined as the ability to respond to unforeseen changes (Sheffi, 2004). The emphasis on supply chain agility appeared in 2001 and was initiated by Harrison (1999) and Christopher (2000). However, agility could be confused with other similar but different concepts, such as adaptability, resilience and flexibility.

Although, agility is the ability to cope with uncertainty and volatility, adaptability is rather used for medium-term changes. Adaptable Supply Chain is used to adapt the design to cope with structural changes in the markets, modify and adapt the supply network to strategies, 
products and technologies, while the strategies put in place try to ensure adaptability in the medium term (Lee, 2004).

Regarding resilience, it aims to mitigate operational risks that could lead to supply failures or disruptions and to ensure continuity in the business of the company. Kott defined resilience as the ability of a system to return to its original state or to change to a new and more desirable state after being disturbed (Kott, 2018). Agility defines the flexibility to deal with volatility and uncertainty in order to respond quickly to customer needs, while resilience defines robustness in the face of identifiable risks in order to ensure business continuity.

The history of agility in the business context begins with the concept of "Flexible Manufacturing Systems". As a result, there is some confusion between agility and flexibility. The distinction between the two terms has not been clearly highlighted, causing confusion and a remarkable lack of common understanding (Christopher et al., 2000).

In the beginning, flexibility in manufacturing was achieved through automation which enable companies to quickly implement changes in the variet or quantities of products. Later, the notion of "manufacturing flexibility" has extended to the broader commercial scale and to the idea of agility - as an organizational practice emerged. According to Christopher \& Towill (2000) flexibility is the main characteristic of agility.

Flexibility refers, in fact, to the ability to react quickly when necessary, whether it is, for example, to identify a new carrier or to call on additional suppliers in the event that the usual supplier is unable to satisfy a demand. Agility goes further, by integrating a capacity for anticipation in the Supply Chain. It presupposes an extended visibility of the chain and a sharing of information between all the actors. Thus, a supplier identifying a probable delay in delivery may seek alternative solutions to offer them to his client, before the latter is affected by an effective and unexpected delay.

Flynn et al. (2010) estimate that external and internal integration is important for manufacturers to understand the uncertainties and environmental changes that ultimately affect flexibility and agility.

\section{Characteristics of the agile supply chain}

To be truly agile, a Supply Chain must have a number of distinctive characteristics. Based on the literature, the key characteristics of the Agile Supply Chain can be identified as follows: responsiveness, flexibility /adaptability and speed (Lin et al., 2006).

On the other hand, according to Kisperska et al. (2008), the market sensitivity, Information integration, process integration and network building remain practices to be implemented to achieve agility in the Supply Chain.

Ron et al. (2017) affirm that improved reactivity is a major capacity of an agile supply chain. They demonstrate this by listing three essential objectives within the framework of the agile supply chain:

- $\quad$ Enriching customer service compared to competitors,

- Mastering change and uncertainty through constantly adaptable structures,

- Evaluating the impact of the population on businesses through information technology.

It is linked to having a direct flow of information from markets and customers using information technology and effective consumer response strategies ("Efficient Consumer Response") to capture data (Christopher et al., 2000). 
Information integration means having the ability to use digital technology to share data between buyers and suppliers, thereby effectively creating a "virtual supply chain". It focuses on unlimited information access and data sharing between suppliers and buyers via the Internet and Electronic Data Interchange (Christopher et al., 2000).He also adds that using the Internet to develop agile supply chains with information sharing, coordination, and postponement has enabled companies to compete successfully in their marketplaces.Process integration describes the collaborative work between buyers and suppliers and concerns the development of joint products and shared information systems. Today, the need for partnerships is increasing; companies tend to outsource many activities for better results.Process integration triggers the need for information transparency, joint strategies and shared visibilities (Christopher et al., 2000)

A network-based supply chain reflects the ability to attract buyers and suppliers to work collaboratively, jointly develop products and share information. It is based on the idea that in order to increase responsiveness and flexibility, companies should develop a capacity to build solid structural relationships with partners in order to guarantee access to information and the sharing of skills (Christopher et al., 2000).

Following the results of our research, we summarize that to achieve the required responsiveness the agile supply chain should contain the following key characteristics:

- $\quad$ Flexibility,

- Market sensitivity,

- a shared virtual network,

- $\quad$ Process integration.

\section{Differences between the agile and lean approach}

The characteristics and principles of a Lean Supply Chain stem from the principles of Toyota Production Systems and the Lean Sigma methodology, which is based on four characteristics:

- Waste disposal,

- Smoothed continuous flow,

- $\quad$ High level of efficiency,

- Quality assurance;

According to Naylor et al. (1999), when companies in a supply chain focus on the enduser, many measures can be considered. However, they can be aggregated as:

- $\quad$ Service;

- Quality;

- Cost;

- Delivery time;

A high level of efficiency consists in adopting a combined approach of reducing costs and improving performance with the principle "do more with less"

Quality assurance focuses on preventing errors in a process by analyzing the causes and supporting a process of improvement. The goal is to reach and maintain the defined quality objectives, to assure customers the safety and quality of its services. Thus, a business can develop through the satisfaction of its customers.

In a Lean management approach, the priority objective sought is cost reduction. A Lean Supply Chain can also compromise a longer delivery time for a lower cost. The company's ability to respond to volatile market demands are called agility, while Lean is "doing more with less" (Christopher et al., 2000). 
Lean "works best in very large, sparse and predictable environments", while Agility "is needed in a less predictable environment where the demand for variety is high" (Christopher et al., 2002).

In addition, to be competitive on the market, a certain product requires a high level of availability like fashion products for example unlike other product or the primary criterion is the low price, as in the case of the consumer product, for example. At this aim, the concept of visibility appears strongly in this fusion of the two paragraphs from the point of increasing the aspect of communication and availability of information, which increases a fruitful partnership in the supply chain. According to Lee (2002) visibility as a fundamental practice of both lean and agile paradigms. To achieve visibility, companies use information sharing techniques with supply chain partners. And adds that the advantage of visibility is expressed in the ease of setting up cost optimization in the lean supply chain thanks to the sharing of information, as for the advantage of visibility in terms of agile supply chain is voice in visibility helps to capture customer requirements and timely order communication throughout the supply chain.

The following table summarizes some of the attributes that distinguish the Lean and Agile approach

Table 1. Difference between Lean and Agile

\begin{tabular}{|l|l|l|}
\hline $\begin{array}{l}\text { Supply chain } \\
\text { characteristics }\end{array}$ & Lean & Agile \\
\hline Objectives & $\begin{array}{l}\text { Cost reduction } \\
\text { Stock reduction }\end{array}$ & $\begin{array}{l}\text { Strong responsiveness to change } \\
\text { Availability of product(or service) adapted } \\
\text { to customer needs }\end{array}$ \\
\hline Key features & $\begin{array}{l}\text { Waste disposal } \\
\text { Continuous pulled stream smoother } \\
\text { High level of efficiency } \\
\text { Quality assurance }\end{array}$ & $\begin{array}{l}\text { Flexibility } \\
\text { Market sensitivity } \\
\text { A shared virtual network } \\
\text { Process integration }\end{array}$ \\
\hline Type of product & $\begin{array}{l}\text { Standard product with a long-life } \\
\text { cycle }\end{array}$ & $\begin{array}{l}\text { Personalized and innovative product with } \\
\text { short life cycle }\end{array}$ \\
\hline Type of request & Little varied and predictable demand & Very varied and unpredictable demand \\
\hline Demarche & $\begin{array}{l}\text { Eliminate wastes, including time, } \\
\text { Work with pulled stream smoother } \\
\text { Do more with less (as long as } \\
\text { customer satisfaction is preserved) } \\
\text { Mastering quality assurance }\end{array}$ & $\begin{array}{l}\text { Rely on information directly from the } \\
\text { market (real demand) } \\
\text { Adopt a virtual organization to seize } \\
\text { profitable opportunities in volatile and / or } \\
\text { new markets. }\end{array}$ \\
\hline
\end{tabular}

Source: Authors' own research

\section{Proposed model for Lean and Agile Supply Chain}

The Lean and Agile Supply Chain process makes it possible to group the lean process with the agile process by positioning a decoupling point.It is considered to be one of the interesting strategies with the aim of limiting the uncertainty of customer orders in the supply chain. The decoupling point is dedicated to the customer order and is personalized according to the customer's wishes (Olhager, 2003).

The decoupling point described the point at which strategic stock it is held as a buffer between fluctuating customer orders and smooth production output (Sun et al, 2008). The concept of customer decoupling point has been widely used to differentiate value-added activities by terms of information on customer demand, which will further highlight the need for different management approaches. The application of this approach is linked to activities located upstream 
or downstream of the decoupling point (Mason et al., 1999). In addition, the customer decoupling point represents a strategic choice for organizations trying to strike a balance between market demands and resource capabilities. This offers support in deciding which activities must been carried out in a situation of uncertainty based on certain information concerning the real demand of clients (Wikner et al, 2007).

Before the concept of customer order decoupling point appeared, most of the production

PICBE | 854 strategies were based solely on the manufacturing on stock applied make to stock strategy or only on the manufacturing on applied order make to order. In make-to-stock systems, the supply chain production strategy is forecast-based and works by pushing products to market. On the other hand, in make-to-order systems, the supply chain production strategy is based on demand driven by market demand.

The customer order decoupling point concept works on the basis of a hybrid make to stock-make to order and is a shock absorber of demand fluctuations (Naylor et al. 1999).

We can say that, in the first phase of manufacturing the product, the concept of lean management is applied, until it reaches a decoupling point. Starting from the decoupling point in which the customer's order is generated at this stage, the concept of agile management is used to adequately meet the needs of the customer and generate value and performance for customer.

Taking into account the study carried out in this paper, the authors propose the following model:

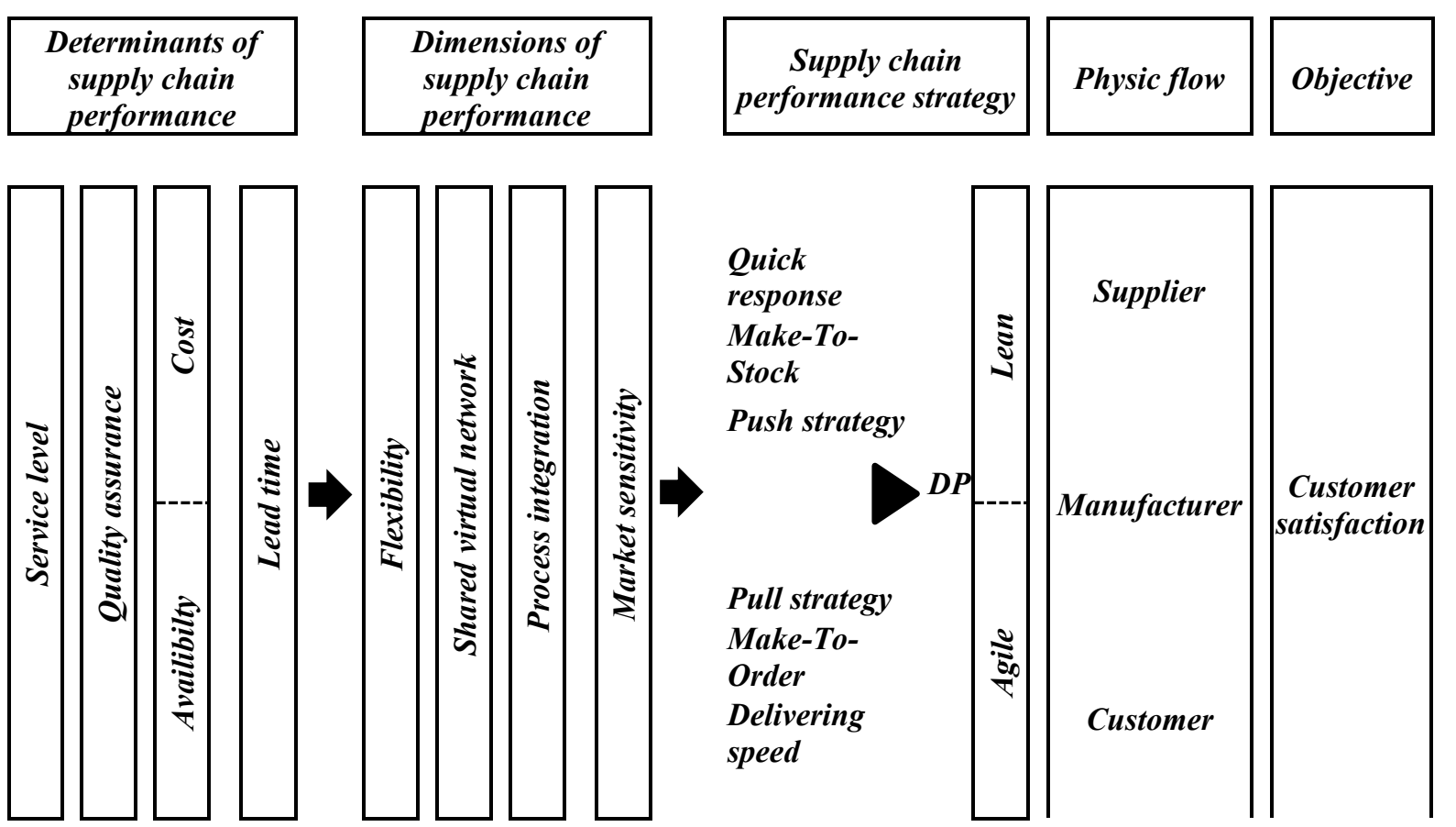

Figure 1. Proposed Lean and Agile model for managing supply chain

\section{Results and discussions}

Source: Source: Authors' own research.

Based on this work, we can define the agility of the Supply Chain as the ability to respond quickly and adequately to short-term changes in demand, supply or the environment. This requires flexibility, responsiveness and efficiency in the Supply Chain. The analysis of the characteristics of Lean and Agile Supply Chains, two management modes often considered 
mutually exclusive, confirms the interest of seeking Agile management of supply chains to meet the need for efficiency and effectiveness, but also flexibility.

Therefore, initiatives to improve the performance of the Supply Chain should focus on adapting supply to demand, thereby reducing costs while improving customer satisfaction. This requires that uncertainty in the Supply Chain must been reduced as much as possible in order to facilitate more predictable upstream demand. Except that there will always be specific supply chains that remain confronted with the situation where they have to accept uncertainty but must develop a strategy that allows them to match supply and demand.

In this case, understanding the specific characteristics of the product type, market requirements and management challenges, will help an organization to design a correct Supply Chain strategy that will guarantee optimal performance and gain a competitive advantage.

This research is a step towards future work, the proposed model is a contribution based on literature, for the objective of improving the supply chain of Moroccan companies, which operate in the automobile industry which are preparing towards future mobility options (electric car), given that the principle of agility is still unclear, the competitive cost approach is the dominant strategy for certain automotive industries in Morocco.

\section{Conclusion}

Supply chain management has become a crucial aspect in the current context of the globalized economy which creates a dynamic of change for companies wishing to survive in the market. this dynamic is limited by the complexity due to the change in the culture of the customer who has become - thanks to the Internet and the appearance of e-commerce - fairly informed and sensitive to the level of value created products and service that the we propose.

The objective of this paper based on the literature is to highlight the Lean and Agile approach as these two paradigms whose links generate a competitive advantage and the performance of the supply chain which determines the survival of the company in its environment. This can only lead through a set of steps that the company must take seriously, while considering as premise criteria such as the effective coordination of all actors in the supply chain including the customer and especially suppliers who are considered a crucial determinant of success, predict a reduced product life cycle, reduce costs, in the face of unstable customer demands, reduce lead time, set up the quality assurance system and increase services, respond quickly and ensure the availability of the product and service to customer requests while maintaining high flexibility.

To reach this, companies must support its employees while including suppliers and customers towards a new mode that promote collaboration, agility, good living together and transversality marked by flexibility to customer requests, by improving the quality of products and services, surely reinforce the performance for the company. However, the company must put in place the tools necessary to achieve a flow of information that has a significant imapct through which the company can base this data, made its strategies based on data and exact information in quality and at the same time. timely, better manage changes and have the high flexibility it survives, namely: IT tools, traceability tools and means of communication throughout the supply chain for timely availability of information allowing it to act and react quickly to any fluctuation by remaining attentive to the market. 


\section{References}

Andelkovic, A., \& Radosavljevic, M. (2018). Improving order-picking process through implementation of workhouse management system, Strategic Management, 23(2), 3-10.

Christopher, M. and Towill, D.R., (2000), Supply Chain Migration from Lean and Functional to Agile and Customised, Int. Jrl. Sup. Change Manag. 5:4, pp 206-213.

Christopher M., (2000), The Agile Supply Chain - Competing in Volatile Markets', Industrial

PICBE $\mid 856$ Marketing Management, vol.29, issue1, pp.37-44.

Christopher M, Peck, H and Towil, D. (2006), A Taxonomy for selecting global supply chain strategies, International Journal of Logistics Management, 17: 2, pp 277-287.

Chandan Deep Singh, R. S., Jaskanwal Singh Mand, Sukhvir Singh. (2013). Application of Lean and JIT Principles in Supply Chain Management. International Journal of Management Research and Business Strategy, 2(1),85-98.

Chen, J. C., et al. (2013) Supply chain management with lean production and RFID application: A case study. Expert Systems with Applications, http:// dx.doi.org/10.1016/ j.eswa.2012.12.047

Christopher, M. and Towill, D.R. (2002), Developing Market Specific Supply Chain Strategies, International Journal of Logistics Management, 13:1, pp. 1-14.

Emory W. Z., Jr.and Ch. M. (2007), Agile Supply Chain Transformation Matrix: A QFD -based Tool for Improving Enterprise Agility, International Journal of Value Chain

Management, Vol.3, No.2, 2007, 281-303

Fachmann, Hunter, (2013). "Lean and Agile supply chain , Retrieved from https:/www.yumpu.com/en/document/read/5247625/lean-and-agilesupply-chain-pdf-fachmann-hunter, ,pp205

Frohlich, M. T. and Westbrook, R. (2001), Arcs of integration: an international study of supply chain strategies, Journal of Operations Management, Vol. 19 No. 2, pp. 185-200.

Flynn, B., Huo, B., and Zhao, X. (2010), The impact of supply chain integration on performance: A contingency and configuration approach, Journal of Operations Management, 28(1), pp. 58-71.

Flynn, B., Huo, B., and Zhao, X. (2010), The impact of supply chain integration on performance: A contingency and configuration approach, Journal of Operations Management, 28(1), pp. 58-71.

Goldman, S. L., Preiss, K., \& Nagel, R. N. (1994). Agile Competitors and Virtual Organizations: Strategies for Enriching the Customer (1st ed.): Wiley. p. 414

Harrison, A., Christopher, M. and van Hoek, R. (1999), Creating the Agile Supply Chain, Institute of Logistics \& Transport, UK

Kamaruddin N. K. and Z. M. Udin, (2009) "Supply chain technology adoption in Malaysian automotive suppliers," J. Manuf. Technol. Manag., vol. 20, no. 3, pp. 385-403, 2009.

Kisperska-Moron, D and Swierczek, A. (2008), The agile capabilities of Polish companies in the supply chain: An empirical study. Int. J. Production Economics. 118 (2009) 217-224 http://dx.doi.org/10.1016/j.ijpe.2008.08.019

Kott A., I. linkov,(2018), ebook: Cyber Resilience of Systems and Networks http://dx.doi.org/10.1007/978-3-319-77492-3

Retrieved from : https://books.google.co.ma/books?id=_fFdDwAAQBAJ\&pg=PA449\&lpg=PA449\&dq=P eck + defined + resilience + as + the + ability + of + a + system + to + return + to + its + original + state + or + to + change + to + a + new + and + more + desirable + state + after + being + disturbed $+($ Peck, +2004$)$ 
\&source=bl\&ots=ziZC-jfzW4\&sig=ACfU3U0vumbW1deBgKTo3LAjTgPLIfO$9 \mathrm{w} \& \mathrm{hl}=\mathrm{en} \& \mathrm{sa}=\mathrm{X} \& \mathrm{ved}=2 \mathrm{ahUKEwj}$ wJbyw-

3mAhXL8eAKHaWvARoQ6AEwA3oECAcQAQ\#v=onepage\&q=Peck\%20defined\%20r esilience $\% 20$ as $\% 20$ the $\% 20$ ability $\% 20$ of $\% 20 a \% 20$ system $\% 20$ to $\% 20$ return $\% 20$ to $\% 20$ its $\%$ 20original $\% 20$ state $\% 20$ or $\% 20$ to $\% 20$ change $\% 20$ to $\% 20 \mathrm{a} \% 20$ new $\% 20$ and $\% 20$ more $\% 20 \mathrm{de}$ sirable\%20state\%20after\%20being\%20disturbed\%20(Peck\%2C\%202004)\&f=false

Ionescu, R. C., Olaru, M., Sargut, K., (2019). Study of the Information Security Impact on the Business Continuity. Proceedings of the 34th IBIMA Conference, 2019, Madrid, Spain, Pag. 4279-4287, ISBN: 978-0-9998551-3-3, https://ibima.org/conference/34th-ibimaconference/\#ffs-tabbed-15.

Lambert D. M., (2008), Supply Chain Management: Processes, Partnerships, Performance, Sarasota, Florida: Supply Chain Management Institute, pp. 53-68, http://dx.doi.org/10.1108/13598541211227153.

Lee, H. L., (2004). THE TRIPLE-A Supply Chain. In: Harvard business review 82.10 (2004), pp. 102-112. (Cit. on pp. 49, 51, 64-66).

Lin, C.T., Chiu, H. \& Chu, P.Y. (2006). Agility index in supply chain. International Journal of Production Economics, 100 (2), 285-299.

http://dx.doi.org/10.1016/j.ijpe.2004.11.013

Marquardt, K., Olaru, M. and Ceausu, I., 2017. Study on the Development of Quality Measurements Models for Steering Business Services in Relation to Customer Satisfaction. Amfiteatru Economic, 19(44), pp. 95-109

Mason R.-Jones and Denis R. Towill, (1999). Using the Information decoupling Point to Improve Supply Chain Performance. Int. Jnl of Logi. Manag., V. 10, Nr 2 (1999) pp.13-26.

Naylor, J. B., Naim, M. M. and Berry, D., (1999), "Leagility: integrating the lean and agile manufacturing paradigms in the total supply chain", International Journal of Production Economics, 62, No.1-2: 107-118.

Olhager, J. 2003. Strategic positioning of the order penetration point. International Journal of Production Economics. 85(3):319-29.

Ron Basu and J. Nevan wright (2017), Managing Global Supply Chains : second edition, p 236 Retrieved from https://books.google.co.ma/books?id=ViMIDwAAQBAJ\&printsec=frontcover\&dq=Mana ging+global+supply+chains:+Second + edition\&hl=en\&sa=X\&ved=0ahUKEwicwNDM6 OnmAhWJ2BQKHV25CP4Q6AEILzAB\#v=onepage\&q=Managing\%20global\%20suppl $\mathrm{y} \% 20$ chains $\% 3 \mathrm{~A} \% 20$ Second $\% 20$ edition\&f=false

Sheffi Y.,(2004). Demand Variability and Supply Chain Flexibility. In: development paths and milestones in modern logistics: sketches of a roadmap (2004). (Cit. on p. 51).

Sun X.Y., P.Ji , L.Y. Suna , Y.L. Wanga., (2008). Positioning multiple decoupling points in a supply network. Int. J. Production Economics, Vol. 113,pp. 943-956

Tortorella, G.L., Miorando, Rogé., Marodin, G. (2017), Lean Supply Chain: pirical research on practices, contexts and performance, International Journal of Production Economics, http://dx.doi.org/10.1016/j.ijpe.2017.07.006.

Vitasek, K., Manrodt, K., and Abbott, J., What makes a lean supply chain, Supply Chain Management Review, vol. 9, no. 7, pp. 39-45, 2005

Wikner, J., Naim, M. M., Rudberg, M., (2007). Exploiting the Order Book for Mass Customized Manufacturing Control Systems with Capacity Limitations. IEEE transactions on engineering management, vol. 54, No. 1, pp. 145-155. 
Zhao, X., Huo, B., Flynn, B., and Yeung, J. (2008), The impact of power and relationship commitment on the integration between manufacturers and customers in a supply chain, Journal of Operations Management,26(3), pp. 368-388.

PICBE | 858 